\title{
Review
}

\section{IgA Nephropathy: A European Perspective in the Corticosteroid Treatment}

\author{
Rosanna Coppo \\ Fondazione Ricerca Molinette, Regina Margherita Hospital, Turin, Italy
}

\section{Keywords}

Corticosteroid therapy · Europe $\cdot \lg A$ nephropathy $\cdot$ Renal pathology $\cdot$ Risk factors for progression

\begin{abstract}
Background: IgA nephropathy (IgAN) is detected in Europe in $22 \%$ of glomerular diseases diagnosed by biopsy. The frequency of IgAN as cause of ESRD in Europe has increased in the last decades, accounting for $35 \%$ of young and adult transplanted patients. These data justify the interest for risk factors and a possible therapeutic approach. Summary: Insight into a European perspective of IgAN was allowed by the multicenter study VALIGA, on 1,147 patients, almost all Caucasians, with follow-up of 4.7 years. The predictive value of mesangial hypercellularity $(M)$, segmental sclerosis $(S)$, tubular atrophy interstitial fibrosis (T) as independent biomarkers of progression was validated. Endocapillary hypercellularity was predictive of increased follow-up proteinuria. Two groups of patients selected by a propensity score to perfectly match for histologic features (MEST) and clinical data treated with renin-angiotensin system blockers (RASBs) and corticosteroids, or RASBs alone were compared and a beneficial effect of corticosteroids in addition to RASB was found in patients with proteinuria $>1 \mathrm{~g} /$ day, with an initial eGFR $<50 \mathrm{~mL} / \mathrm{min} / 1.73 \mathrm{~m}^{2}$. On the contrary, the STOP-IgAN RCT found that immunosuppressive therapy in addition to opti-
\end{abstract}

\section{KARGER}

(c) 2018 S. Karger AG, Basel

E-Mail karger@karger.com

www.karger.com/kdd mal supportive care did not provide substantial kidney-related benefits in European patients with IgAN, because there was no difference in the rate of decrease in eGFR, although corticosteroid/immunosuppressive therapy induced complete remission of proteinuria more frequently than supportive care alone. The NEFIGAN trial evaluated a targeted release formulation of budesonide (TRF budesonide) delivering the drug in the distal ileum. TRF budesonide, additionally to optimized RAS blockade, reduced proteinuria and maintained eGFR in IgAN patients, suggesting a reduced risk of future progression to ESRD. Key Messages: In Europe, there is a reasoned search of a balanced approach to corticosteroid therapy for patients with IgAN, with particular attention to selecting the patients at risk of progression while limiting the unwanted systemic adverse events.

(c) 2018 S. Karger AG, Basel

\section{Introduction}

IgAN is the most frequent glomerular disease in $\mathrm{Eu}-$ rope, with an incidence of 8 to 25 new cases/year/pmarp (per million of age-related population) in adults and 3 to 5 new cases/year/pmarp in children [1]. In Europe, the frequency of IgAN ranges from 19 to $51 \%$ of renal biopsies performed in glomerular diseases in various countries [2-4]. From the results of the International Kidney 
Biopsy Survey (IKSB) on glomerular disease frequencies, analyzing 42,603 renal biopsies in four continents, IgAN has a high frequency in Europe, though less than in Asia, accounting for 22 and $39 \%$, respectively, of all glomerular diseases diagnosed by renal biopsies [5]. A genetic background is likely to play a role, since the increase in incidence of IgAN with eastward and northward distance from Africa is correlated with an increase of the 7-SNP genetic risk score [6]. However, according to the IKSB survey, IgAN frequencies differed by continent, even among patients of the same race/ethnicity, being lower in whites in North America in respect to those in Europe (14 vs. $25 \%, p<0.001)$ or in Asians in North America to those in Asia (27 vs. $40 \%, p<0.001)$. Regional dietetic and microbiota environmental differences and lifestyle factors may influence the different incidence of IgAN in the same ethnic groups, but most of all, local biopsy policies influence IgAN epidemiology, as reported by the Scottish registry almost 20 years ago [7]. The frequency is even more strongly influenced by the present renal biopsy policy first adopted in the US and nowadays followed in some (though not all) European countries as well, which has a trend to not biopsy a patient with chronic urinary abnormalities before a trial with renin-angiotensin system blockers (RASB) and the manifestation of persistent relevant proteinuria.

In Europe, IgAN is a relevant disease ending in endstage renal failure and needing renal replacement treatment (RRT). The ERA-EDTA Registry reported from countries with a long-term follow-up since 1990 (including Denmark, Finland, Iceland, Norway, the Netherlands, Sweden, and UK/Scotland) showed an increase in incidence of RRT in patients with primary IgAN from 4 to $6 \%$ of all subjects entering the program/year, while IgA vasculitis (Henoch-Schoenlein purpura nephritis) maintained the same incidence of $1 \%$ over the last decades. According to the ERA-EDTA Registry, IgAN is the original disease in $35 \%$ of 20 - to 44 -year-old transplanted patients in Europe. These data justify the interest of European nephrology for IgAN and particularly for the risk factors for progression and a possible therapeutic approach.

\section{Presentation of IgAN in Europe Focusing on Pathology Risk Factors Derived from the VALIGA Study on 1,147 Patients with IgAN}

The Validation Study of the Oxford Classification of IgAN (VALIGA) [8] created a large European database of patients with IgAN followed over a prolonged time frame, which included clinical, laboratory, and histological data. The study was initially aimed to validate the Oxford Classification of IgAN in a European cohort. The MEST lesions - mesangial (M) or endocapillary (E) hypercellularity, segmental glomerulosclerosis (S), and tubular atrophy/interstitial fibrosis $(\mathrm{T})$ - predicted renal outcome independently of clinical data at renal biopsy and during follow-up and were valid in children as well as in adults $[9,10]$. However, the Oxford cohort was rather limited including 265 adults and children only from 15 centers in 11 countries [11]. Several validation studies have been performed in the following years [12]. The VALIGA study validated in Europe the Oxford classification in cohorts with different presentations and treatments expanding the enrollment criteria of the original study, including patients with mild proteinuria $<0.5 \mathrm{~g} /$ day and those with follow-up shorter than 1 year, if ending in ESRD [8].

The multicenter VALIGA study involved 1,147 European patients, almost all Caucasians, with a follow-up of 4.7 years. In this large cohort, the value of $\mathrm{M}, \mathrm{S}$, and $\mathrm{T}$ as independent histological biomarkers of progression was confirmed. The strongest predictive value was the presence of irreversible extensive T lesions in $>25 \%$ of the renal biopsy tissue (T1 and T2), but several data indicated also the value of reversible pathology risk factors.

In this European validation study, the independent value of endocapillary hypercellularity (E1) was not detected, but there was an important bias of a greater use of corticosteroid/immunosuppressive drugs in patients with E1. However, in patients with mild proteinuria $(<0.5$ $\mathrm{g} /$ day), E1 lesions were associated with significantly lower survival from a $50 \%$ reduction of e-GFR/ESRD (combined end point) and were risk factors for developing higher proteinuria levels ( $>1 \mathrm{~g} /$ day) [8]. In a single-center European study investigating patients with IgAN without corticosteroid or immunosuppressive treatment irrespective of clinical features at renal biopsy and followed for 6 years, E1 was the best predictor of renal survival [13]. This was indicated also by a Chinese study of repeated renal biopsies after treatment with various combinations of immunosuppressive drugs, in which a significant decrease in E1 lesions was reported [14]. In a recent European study, E1 was found to be reduced by mycophenolate mofetil treatment in repeated biopsies [15]. In conclusion, in Europe, the value of endocapillary hypercellularity as risk factor for IgAN progression and the possible benefit of corticosteroid/immunosuppressive treatment is taken into account, while waiting for the results of a future specific RCT. 
Mesangial hypercellularity M1 was found in the VALIGA study to be predictive of outcome also in the subgroup of patients with eGFR $<30 \mathrm{~mL} / \mathrm{min}$ [8]. The presence of M1 was a histological marker predicting benefits of steroid therapy [16]. In 261 young subjects aged $<23$ years enrolled in VALIGA, the presence of M1 was a significant risk for survival from the combined end point and for high time-averaged proteinuria during the subsequent follow-up [17]. The remission of proteinuria to values $<0.5 \mathrm{~g} /$ day $/ 1.73 \mathrm{~m}^{2}$ was significantly predicted by the absence of mesangial proliferation, preserved GFR at renal biopsy $\left(>90 \mathrm{~mL} / \mathrm{min} / 1.73 \mathrm{~m}^{2}\right)$, and use of corticosteroid/immunosuppressive therapy. These data indicate that mesangial hypercellularity in VALIGA children and young subjects is a risk factor for progression and may be reversed by steroid therapy. Almost 20 years ago. a Japanese RCT [18] enrolling children with mesangial hypercellularity in $>80 \%$ of glomeruli demonstrated a significant benefit of 2 years of prednisone and azathioprine therapy in addition to anticoagulation and antiplatelet treatment in comparison to anticoagulation and antiplatelet therapy only. The mesangial proliferation significantly decreased in children treated by corticosteroids. Ten years after the end of the treatment, the renal survival was significantly better in children previously treated with corticosteroids/immunosuppressors [19]. In Europe, the present tendency is to consider the presence of M1 as a possible marker of the need of corticosteroid therapy particularly in children and young subjects even with mild proteinuria, as suggested also from the collaborative study which pooled data from VALIGA, Chinese, Japanese, and North American cohorts [16]. This study proved that the presence of M1 was a significant risk factor for progression even in patients with proteinuria $<1$ $\mathrm{g}$ /day at renal biopsy, which showed a decline similar to that of patients with persistent time-averaged proteinuria of 1-2 g/day for 2 years, hence fully eligible for corticosteroid treatment according to KDIGO 2012 [20].

Segmental glomerular sclerosis (S1) In VALIGA European patients was a risk factor for progression [8]. In a recent European study, podocyte hypertrophy or sclerosis at the tubular pole (tip lesion), features typically associated with podocytopathies, was correlated with more proteinuria at presentation and more rapid decline in renal function if not treated with corticosteroids/immunosuppressors [21]. The revised Oxford Classification [22] recommends reporting segmental sclerosis with/without podocyte hypertrophy/tip lesions. In the VALIGA study, propensity score-matched patients with $\mathrm{S} 1$ had a significant benefit from corticosteroid/immunosuppressive therapy [23]. These results are of interest, while in Europe, we are waiting for a RCT demonstrating the potential benefits of corticosteroids/immunosuppressors in IgAN with S1 podocytopathic lesions.

Crescents lesions were not found to have a prognostic value at multivariate analysis in the VALIGA study, but there was a bias of a great use of immunosuppressive treatment in these patients. A multicenter study analyzing pooled data from the Oxford, VALIGA, Chinese, and Japanese cohorts (3,096 patients, one-third with crescents) produced an interesting new analysis of crescents as a risk factor for IgAN [24]. Crescents were predictive of the combined event of $50 \%$ decline in GFR or ESRD but only in patients not receiving immunosuppressors. Patients with $>25 \%$ of crescents were at risk even if treated with immunosuppressive therapy. This study indicates the need to add crescent scores $(\mathrm{C} 0, \mathrm{C} 1$, and $\mathrm{C} 2)$ to the Oxford MEST scores [22]. A new MEST-C score has been proposed and largely adopted in Europe. In Europe, patients with crescents in $>25 \%$ of glomeruli are most often treated with corticosteroid/immunosuppressive therapy.

\section{Indications for Corticosteroid Therapy for IgAN in Europe Derived from the Observational VALIGA Study, the STOP-IgAN, and the NEFIGAN RCTs}

\section{VALIGA Study}

The large cohort of European patients with IgAN observed in the VALIGA study allowed the identification of two groups of 184 patients, each selected by a propensity score which perfectly matched for histologic features (MEST scores) and clinical data: one group was treated with RASBs and corticosteroids, and the other with RASBs alone [23]. Patients treated with corticosteroids and RASBs had better outcomes compared with matched patients with RASBs alone for survival to the combined end point $(p<0.01)$, rate of renal function decline $(p=$ $0.004)$, and decrease in proteinuria during the follow-up $(p<0.001)$, showing a significantly higher frequency of reducing proteinuria $<1 \mathrm{~g} /$ day. The benefits of corticosteroids increased according to pretreatment-persistent levels of proteinuria. The greatest protective effect was observed when proteinuria was $>3 \mathrm{~g} /$ day $(p=0.001)$ or $>1$ $\mathrm{g} /$ day $(p=0.03)$, whereas no difference between treatments was found when proteinuria was $<1 \mathrm{~g} /$ day. A lower rate of renal function decline and a greater reduction in proteinuria were observed when patients with $\mathrm{M} 1, \mathrm{~S} 1$, and $\mathrm{T} 1$ scores were treated with corticosteroids compared with those treated with RASB alone. 
This analysis of the European VALIGA patients led to the conclusion of a beneficial effect of corticosteroids in addition to RASB in IgAN patients with proteinuria $>1$ $\mathrm{g} /$ day, even with an initial eGFR $<50 \mathrm{~mL} / \mathrm{min} / 1.73 \mathrm{~m}^{2}$. However, this was a retrospective cohort study and the results of prospective RCT were expected in Europe as in the whole nephrologist community. The results of the STOP-IgAN RCT were publishes after a few months in 2015 [25].

\section{STOP-IgAN RCT}

The STOP-IgAN trial [25] tested the hypothesis that in patients with IgAN, corticosteroid/immunosuppressive therapy added to comprehensive supportive care would be superior to supportive care alone. The primary end point, after 3 years, was full clinical remission $(<0.2$ $\mathrm{mg} / \mathrm{mg}$ proteinuria/cr with stable eGFR) or decrease in the eGFR $>15 \mathrm{~mL} / \mathrm{min} / 1.73 \mathrm{~m}^{2}$. Eligible patients had proteinuria $>0.75$ and $<3.5 \mathrm{~g} /$ day and eGFR $>30 \mathrm{~mL} /$ $\min / 1.73 \mathrm{~m}^{2}$. The randomization excluded $34 \%$ of responders to the 6-month run-in phase with supportive care who showed a decline in proteinuria to values $<0.75$ $\mathrm{g} /$ day) and $12 \%$ of high-risk patients with higher proteinuria levels and fast eGFR decline. Patients were randomized to continue supportive care or to receive corticoste$\mathrm{roid} / \mathrm{immunosuppressive} \mathrm{therapy;} 55$ patients with eGFR of $>60 \mathrm{~mL} / \mathrm{min}$ received corticosteroid monotherapy for 6 months ( 9 methylprednisolone pulses and oral prednisolone at $0.5 \mathrm{mg} / \mathrm{kg}$ on alternate days), and 27 patients with eGFR $>30$ and $<59 \mathrm{~mL} / \mathrm{min}$ received, for 36 months, $1.5 \mathrm{mg} / \mathrm{kg} /$ day cyclophosphamide followed by $1.5 \mathrm{mg} /$ $\mathrm{kg}$ /day azathioprine plus $40 \mathrm{mg} /$ day oral prednisolone, waning over 36 months. At the end of the 3 years, $5 \%$ of patients in the supportive care group had full clinical remission ( $p=0.001$ ) versus $17 \%$ in the immunosuppression group ( $p=0.001)$; however, no difference between the two groups was found in the decrease of eGFR $>15$ $\mathrm{mL} / \mathrm{min} / 1.73 \mathrm{~m}^{2}$ (28 vs. $26 \%$, respectively). Patients in the corticosteroid monotherapy group reached significantly lower mean proteinuria than those in the supportive care alone, but data were pooled together with those in patients with advanced CKD receiving the combination therapy, and no difference in proteinuria or GFR decline was found at 3 years. Microscopic hematuria disappeared more frequently in the treatment group at the end of the RCT.

The STOP-IgAN RCT found that immunosuppressive therapy in addition to optimal supportive care did not provide substantial kidney-related benefits in European patients with IgAN, because there was no difference in the rate of decrease in eGFR, although corticosteroid/immunosuppressive therapy induced complete remission of proteinuria more frequently than supportive care alone.

The results of this RCT were of great relevance, though some flaws were pointed out by the nephrologist community (in Europe as well as in other continents) [26]. The patients enrolled had a very limited renal function decline of $-1.6 \mathrm{~mL} / \mathrm{min} /$ year, rendering it difficult to prove the benefits of any additional treatment after a relatively short follow-up [26]. The STOP-IgAN trial was primarily powered to detect a difference in clinical remission, which it did in favor of immunosuppression [27], showing a reduction in proteinuria which has been validated by a recent meta-analysis [28]. The trial was too short and underpowered to detect the changes in renal function which have been validated as surrogate markers of ESRD such as a $50 \%$ decline in eGFR. The two groups, receiving two immunosuppressive regimens, had different modification of proteinuria, which was good in the group with relatively preserved eGFR and receiving corticosteroid monotherapy: the effects on eGFR decline on the longterm course are expected to be different [26]. In the VALIGA, the protective effect of proteinuria $>0.5 \mathrm{~g} /$ day and $<1 \mathrm{~g} /$ day on the combined end point was detected after 10 years [8].

The authors of the STOP-IgAN RCT concluded that immunosuppressive therapy in addition to optimal supportive care would not provide substantial kidney-related benefits in European patients with high-risk IgAN, because there was no difference in the rate of decrease in eGFR, although corticosteroid/immunosuppressive therapy induced complete remission of proteinuria more frequently than supportive care alone. However, there were many flaws as detailed above, rendering the absolutely negative conclusion about the ineffectiveness of corticosteroid/immunosuppressive therapy in IgAN not fully acceptable.

Notably, the STOP-IgAN provided relevant information, demonstrating the strong benefit of aggressive optimization of supportive measures that result in a sustained reduction in proteinuria and a low short-term risk of renal function decline. However, the issue of side effects was raised (one death due to pneumogenic sepsis and two neoplasms in the immunosuppressive group), which was further claimed by the results of the TESTING RCT in mostly Chinese patients [29]. The latter trial was prematurely discontinued because of an imbalance of adverse events, mostly infectious, in the corticosteroid arm, in spite of greater protection against renal failure progression. Hence, great interest is focused in Europe and ev- 
erywhere on the possible beneficial effects of drugs provided with less systemic side effects than corticosteroid/ immunosuppressive regimens.

\section{NEFIGAN RCT}

Altered function of gut-associated lymphoid tissue may play an important role in the immunopathogenesis of IgAN as reported by several European studies in the past [30]. An enteric formulation of budesonide has been developed that targets release of the drug in the distal ileum wherein it affects local lymphoid tissue, with theoretically high first-pass metabolism in the liver resulting in low systemic exposure. The NEFIGAN trial compared this novel targeted release formulation of budesonide (TRF budesonide) with placebo [31]. The RCT was double blinded and placebo controlled and included a 6-month run-in, 9-month treatment, and 3-month follow-up period. No study of intestinal immunity was performed. TRF budesonide ( $16 \mathrm{mg} /$ day; $8 \mathrm{mg} /$ day) was compared with placebo in patients with persistent proteinuria despite optimized RAS blockade. End points included mean change from baseline in urine protein creatinine ratio (UPCR) at 9 months (primary) and change in eGFR. At 9 months, mean UPCR had decreased by $24 \%$ in all TRF budesonide-treated patients combined but had increased by $2.7 \%$ in placebo-treated patients $(p=0.006)$. The effect was sustained throughout follow-up for $16 \mathrm{mg} /$ day; mean UPCR decreased 32\% from baseline at 12 months versus an increase of $0.5 \%$ for placebo. At 9 months, eGFR stabilized with TRF budesonide but decreased 9.8\% with placebo (TRF budesonide vs. placebo: $p=0.001)$. No increase in serious adverse events and particularly infections were reported in treated patients.

The conclusion was that TRF budesonide, additional to optimized RAS blockade, reduced proteinuria and maintained eGFR in IgAN patients, indicating a reduced risk of future progression to ESRD.

Additional studies will be needed to determine if enteric budesonide can improve renal outcome in terms of GFR protection over a long follow-up without the risk of the systemic toxicity that was observed in the STOPIgAN and TESTING trials.

\section{Safety of Treatment of IgAN with Immunosuppressors}

In a meta-analysis on 245 patients with IgAN from 9 RCTs treated with corticosteroids, the incidence of severe adverse events was 6.9\% (mostly hypertension and diabe- tes and rarely, gastrointestinal bleeding) [32]. In a recent meta-analysis on 325 patients treated with intravenous steroid pulses alone or in combination with azathioprine, the risk of major adverse events was low in patients with normal renal function (2.9\%) but increased in those with impaired renal function (15.4\%), particularly when adding azathioprine (30\%).

In the STOP trial, adverse events were more common than in prior trials. Serious adverse events had similar frequencies in the two study groups, but patients treated with immunosuppression reported more cases of infection, though not significantly different from control patients (36 vs. $40 \%$ ), impaired glucose metabolism, and body weight gain. Moreover, two patients had malignant neoplasms during combined immunosuppression. In the TESTING trial, the frequency of adverse events was highly different in treated and placebo groups: $14.7 \%$ in the methylprednisolone group versus $3.2 \%$ in the placebo group ( $p=0.001$ ), mostly due to serious infections (8 vs. $0 \% ; p<0.001)$, including 2 deaths.

The STOP-IgAN trial enrolled $33 \%$ of patients with eGFR $<60 \mathrm{~mL} / \mathrm{min}$ and in the TESTING, $38 \%$ of patients had initial eGFR $<50 \mathrm{~mL} / \mathrm{min}$ : the percentage of patients exposed to higher risk of corticosteroid/immunosuppressive therapy because of low FGR was higher than in previous RCTs. Moreover, the frequency of side effects is also increased in protocols with exposure to corticosteroids/ immunosuppressive drugs longer than 6 months: the STOP trial exposed the subgroup of patients with initial eGFR $<60 \mathrm{~mL} / \mathrm{min}$ to 3 years of immunosuppression.

The NEFIGAN RCT was expected to carry a low risk of adverse events, and indeed no serious infection complication was reported, and no statistical difference in other adverse events was observed. The frequency of adverse events was high also in the placebo group (84\%), similarly to what was observed in the STOP trial (36\% of serious adverse events in the placebo group). The frequency of any side effect was high in the treatment as well as in the placebo groups in recent RCTs in which adverse event reports were solicited.

\section{Conclusion from Recent European Studies on Corticosteroid Treatment of Patients with IgAN}

- A protracted and rigorous supportive care, targeting RAS for BP and proteinuria, metabolic and lifestyle targets can be of benefit in one-third of patients with proteinuria $<0.75-3.5 \mathrm{~g} /$ day and not at high risk of rapid progression [25]. 
- Is additional corticosteroid therapy needed? The STOP-IgAN trial provided a negative answer, but a personalized approach may be proposed: no when proteinuria $0.75-1.5 \mathrm{~g} /$ day and negative MEST scores [16]; yes when IgAN is in progression with rapid loss of GFR or when crescents are present in $>25 \%$ of glomeruli (C1) [24]; probably yes when risk factors are present, with persistent proteinuria $>1 \mathrm{~g} /$ day [8] or when proteinuria $<1 \mathrm{~g} /$ day with $\mathrm{M} 1$ or $\mathrm{E} 1$ or $\mathrm{S} 1$ with podocytopathy [22].

- Addition of corticosteroids to supportive care induces reduction in proteinuria and possible reno-protective effects on the long term with increase in adverse events but mostly in cases with impaired renal function $[8,28$, 33].

- The enteric formulation of budesonide seems to provide similar favorable results without serious side effects of steroids [31].

- Addition of alkylating agents/antimetabolites to corticosteroids is not indicated in non-vasculitis-like progressive forms, particularly when GFR $<50 \mathrm{~mL} /$ $\mathrm{min} / 1.73 \mathrm{~m}^{2}[25,33]$.

\section{Conflict of Interest Statement}

The author has no conflict of interest to declare.

\section{References}

1 McGrogan A, Franssen CF, de Vries CS: The incidence of primary glomerulonephritis worldwide: a systematic review of the literature. Nephrol Dial Transplant 2011;26:414430.

2 Zaza G, Bernich P, Lupo A; 'Triveneto’ Register of Renal Biopsies (TVRRB): Incidence of primary glomerulonephritis in a large NorthEastern Italian area: a 13-year renal biopsy study. Nephrol Dial Transplant 2013;2:367372.

-3 Verde E, Quiroga B, Rivera F, López-Gómez JM: Renal biopsy in very elderly patients: data from the Spanish Registry of Glomerulonephritis. Am J Nephrol 2012;3:230-237.

4 Maixnerova D, Bauerova L, Skibova J, Rysava R, Reiterova J, Merta M, Honsova E, Tesar V: The retrospective analysis of 343 Czech patients with IgA nephropathy - one centre experience. Nephrol Dial Transplant 2012;27: 1492-1498.

-5 O’Shaughnessy M, Hogan S, Bawana D, Coppo R, Fogo A, Jennette C: Glomerular disease frequencies by race, sex and region: results from the International Kidney Biopsy Survey. Nephrol Dial Transpl 2017, DOI: 10.1093/ ndt/gfx189.

6 Gharavi AG, Kiryluk K, Choi M, Li Y, Hou P, Xie J, Sanna-Cherchi S, Men CJ, Julian BA, Wyatt RJ, Novak J, He JC, Wang H, Lv J, Zhu L, Wang W, Wang Z, Yasuno K, Gunel M, Mane S, Umlauf S, Tikhonova I, Beerman I, Savoldi S, Magistroni R, Ghiggeri GM, Bodria M, Lugani F, Ravani P, Ponticelli C, Allegri L, Boscutti G, Frasca G, Amore A, Peruzzi L, Coppo R, Izzi C, Viola BF, Prati E, Salvadori M, Mignani R, Gesualdo L, Bertinetto F, Mesiano P, Amoroso A, Scolari F, Chen N, Zhang H, Lifton RP: Genome-wide association study identifies susceptibility loci for IgA nephropathy. Nat Genet 2011;43:321-327.

7 McQuarrie EP, Mackinnon B, Young B, Yeoman L, Stewart G, Fleming S, Robertson S,
Simpson K, Fox J, Geddes CC; Scottish Renal Biopsy Registry: Centre variation in incidence, indication and diagnosis of adult native renal biopsy in Scotland. Nephrol Dial Transplant 2009;24:1524-1528.

8 Coppo R, Troyanov S, Bellur S, Cattran D, Cook HT, Feehally J, Roberts IS, Morando L, Camilla R, Tesar V, Lunberg S, Gesualdo L, Emma F, Rollino C, Amore A, Praga M, Feriozzi S, Segoloni G, Pani A, Cancarini G, Durlik M, Moggia E, Mazzucco G, Giannakakis C, Honsova E, Sundelin BB, Di Palma AM, Ferrario F,Gutierrez E, Asunis AM, Barratt J, Tardanico R, Perkowska-Ptasinska A; VALIGA study of the ERA-EDTA Immunonephrology Working Group: Validation of the Oxford classification of IgA nephropathy in cohorts with different presentations and treatments. Kidney Int 2014;86:828-836.

-9 Cattran DC, Coppo R, Cook HT, Feehally J, Roberts IS, Troyanov S, Alpers CE, Amore A, Barratt J, Berthoux F, Bonsib S, Bruijn JA, D'Agati V, D'Amico G, Emancipator S, Emma F, Ferrario F, Fervenza FC, Florquin S, Fogo A, Geddes CC, Groene HJ, Haas M, Herzenberg AM, Hill PA, Hogg RJ, Hsu SI, Jennette JC, Joh K, Julian BA, Kawamura T, Lai FM, Leung CB, Li LS, Li PK, Liu ZH, Mackinnon B, Mezzano S, Schena FP, Tomino Y, Walker PD, Wang H, Weening JJ, Yoshikawa $\mathrm{N}$, Zhang: The Oxford classification of IgA nephropathy: rationale, clinicopathological correlations, and classification. Kidney Int 2009;76:534-545.

10 Coppo R, Troyanov S, Camilla R, Hogg RJ, Cattran DC, Cook HT, Feehally J, Roberts IS, Amore A, Alpers CE, Barratt J, Berthoux F, Bonsib S, Bruijn JA, D’Agati V, D’Amico G, Emancipator SN, Emma F, Ferrario F, Fervenza FC, Florquin S, Fogo AB, Geddes CC, Groene HJ, Haas M, Herzenberg AM, Hill PA, Hsu SI, Jennette JC, Joh K, Julian BA, Kawamura T, Lai FM, Li LS, Li PK, Liu ZH,
Mezzano S, Schena FP, Tomino Y, Walker PD, Wang H, Weening JJ, Yoshikawa N, Zhang H: The Oxford IgA nephropathy clinicopathological classification is valid for children as well as adults. Kidney Int 2010;77: 921-927.

11 Roberts IS, Cook HT, Troyanov S, Alpers CE, Amore A, Barratt J, Berthoux F, Bonsib S, Bruijn JA, Cattran DC, Coppo R, D'Agati V, D'Amico G, Emancipator S, Emma F, Feehally J, Ferrario F, Fervenza FC, Florquin S, Fogo A, Geddes CC, Groene HJ, Haas M, Herzenberg AM, Hill PA, Hogg RJ, Hsu SI, Jennette JC, Joh K, Julian BA, Kawamura T, Lai FM, Li LS, Li PK, Liu ZH, Mackinnon B, Mezzano S, Schena FP, Tomino Y, Walker PD, Wang H, Weening JJ, Yoshikawa N, Zhang H; Working Group of the International IgA Nephropathy Network and the Renal Pathology Society: The Oxford classification of IgA nephropathy: pathology definitions, correlations, and reproducibility. Kidney Int 2009;76:546-556.

12 Soares MF, Roberts IS: IgA nephropathy: an update. Curr Opin Nephrol Hypertens 2017; 26:165-171.

13 Chakera A, MacEwen C, Bellur SS, Chompuk LO, Lunn D, Roberts ISD: Prognostic value of endocapillary hypercellularity in IgA nephropathy patients with no immunosuppression. J Nephrol 2016;29:367-375.

14 Shen XH, Liang SS, Chen HM, Le WB, Jiang $\mathrm{S}$, Zeng CH, Zhou ML, Zhang HT, Liu ZH: Reversal of active glomerular lesions after immunosuppressive therapy in patients with IgA nephropathy: a repeat-biopsy based observation. J Nephrol 2015;28:441-449.

-15 Beckwith H, Medjeral-Thomas N, Galliford J, Griffith M, Levy J, Lightstone L, Palmer A, Roufosse C, Pusey C, Cook HT, Cairns T: Mycophenolate mofetil therapy in immunoglobulin A nephropathy: histological changes after treatment. Nephrol Dial Transplant 2017; 32(suppl 1):i123-i128. 
-16 Barbour SJ, Espino-Hernandez G, Reich HN, Coppo R, Roberts IS, Feehally J, Herzenberg AM, Cattran DC; Oxford Derivation, North American Validation and VALIGA Consortia: The MEST score provides earlier risk prediction in IgA nephropathy. Kidney Int 2016; 89:167-175.

17 Coppo R, Lofaro D, Camilla RR, Bellur S, Cattran D, Cook HT, Roberts IS, Peruzzi L, Amore A, Emma F, Fuiano L, Berg U, Topaloglu R, Bilginer Y, Gesualdo L, Polci R, Mizerska-Wasiak M, Caliskan Y, Lundberg S, Cancarini G, Geddes C, Wetzels J, Wiecek A, Durlik M, Cusinato S, Rollino C, Maggio M, Praga M, K Smerud H, Tesar V, Maixnerova D, Barratt J, Papalia T, Bonofiglio R, Mazzucco G, Giannakakis C, Soderberg M, Orhan D, Di Palma AM, Maldyk J, Ozluk Y, Sudelin B, Tardanico R, Kipgen D, Steenbergen E, Karkoszka H, Perkowska-Ptasinska A, Ferrario F, Gutierrez E, Honsova E: Risk factors for progression in children and young adults with IgA nephropathy: an analysis of 261 cases from the VALIGA European cohort. Pediatr Nephrol 2017;32:139-150.

- 18 Yoshikawa N, Ito H, Sakai T, Takekoshi Y, Honda M, Awazu M, Ito K, Iitaka K, Koitabashi Y, Yamaoka K, Nakagawa K, Nakamura H, Matsuyama S, Seino Y, Takeda N, Hattori S, Ninomiya M: A controlled trial of combined therapy for newly diagnosed severe childhood IgA nephropathy. The Japanese Pediatric IgA Nephropathy Treatment Study Group. J Am Soc Nephrol 1999;10:101-109.

-19 Kamei K, Nakanishi K, Ito S, Saito M, Sako M, Ishikura K, Hataya H, Honda M, Iijima K, Yoshikawa N; Japanese Pediatric IgA Nephropathy Treatment Study Group: Long-term results of a randomized controlled trial in childhood IgA nephropathy. Clin J Am Soc Nephrol 2011;6:1301-1307.

20 Kidney Disease: Improving Global Outcomes (KDIGO) Glomerulonephritis Work Group: KDIGO Clinical Practice Guideline for Glomerulonephritis. Immunoglobulin A nephropathy. Kidney Int Suppl 2012;2:139-274.
Bellur SS, Lepeytre F, Vorobyeva O, Troyanov $\mathrm{S}$, Cook HT, Roberts IS; International IgA Nephropathy Working Group: Evidence from the Oxford Classification cohort supports the clinical value of subclassification of focal segmental glomerulosclerosis in IgA nephropathy. Kidney Int 2017;91:235-243.

22 Trimarchi H, Barratt J, Cattran DC, Cook HT, Coppo R, Haas M, Liu ZH, Roberts IS, Yuzawa Y, Zhang H, Feehally J; IgAN Classification Working Group of the International IgA Nephropathy Network and the Renal Pathology Society; Conference Participants: Oxford Classification of IgA nephropathy 2016: an update from the IgA Nephropathy Classification Working Group. Kidney Int 2017;91: 1014-1021.

23 Tesar V, Troyanov S, Bellur S, Verhave JC, Cook HT, Feehally J, Roberts IS, Cattran D, Coppo R; VALIGA study of the ERA-EDTA Immunonephrology Working Group: Corticosteroids in IgA nephropathy: a retrospective analysis from the VALIGA study. J Am Soc Nephrol 2015;26:2248-2258.

24 Haas M, Verhave JC, Liu ZH, Alpers CE, Barratt J, Becker JU, Cattran D, Cook HT, Coppo R, Feehally J, Pani A, Perkowska-Ptasinska A, Roberts IS, Soares MF, Trimarchi H, Wang S, Yuzawa Y, Zhang H, Troyanov S, Katafuchi R: A multicenter study of the predictive value of crescents in IgA nephropathy. J Am Soc Nephrol 2017;28:691-701.

25 Rauen T, Eitner F, Fitzner C, Sommerer C, Zeier M, Otte B, Panzer U, Peters H, Benck U, Mertens PR, Kuhlmann U, Witzke O, Gross O, Vielhauer V, Mann JF, Hilgers RD, Floege J; STOP-IgAN Investigators: Intensive supportive care plus immunosuppression in IgA nephropathy. N Engl J Med 2015;373:22252236.

26 Coppo R: Corticosteroids in IgA nephropathy: lessons from recent studies. J Am Soc Nephrol 2017;28:25-33.

27 Barbour S, Feehally J: An update on the treatment of IgA nephropathy. Curr Opin Nephrol Hypertens 2017;26:319-326.
28 Inker LA, Mondal H, Greene T, Masaschi T, Locatelli F, Schena FP, Katafuchi R, Appel GB, Maes BD, Li PK, Praga M, Del Vecchio L, Andrulli S, Manno C, Gutierrez E, Mercer A, Carroll KJ, Schmid CH, Levey AS: Early change in urine protein as a surrogate end point in studies of IgA nephropathy: an individual-patient meta-analysis. Am J Kidney Dis 2016;68:392-401.

29 Lv J, Zhang H, Wong MG, Jardine MJ, Hladunewich $\mathrm{M}$, Jha V, Monaghan $\mathrm{H}$, Zhao M, Barbour S, Reich H, Cattran D, Glassock R, Levin A, Wheeler D, Woodward M, Billot L, Chan TM, Liu ZH, Johnson DW, Cass A, Feehally J, Floege J, Remuzzi G, Wu Y, Agarwal R, Wang HY, Perkovic V; TESTING Study Group: Effect of oral methylprednisolone on clinical outcomes in patients with IgA nephropathy: the TESTING randomized clinical trial. JAMA 2017;318:432-442.

30 Coppo R: The intestine-renal connection in IgA nephropathy. Nephrol Dial Transplant 2015;30:360-366.

- 31 Fellström BC, Barratt J, Cook H, Coppo R, Feehally J, de Fijter JW, Floege J, Hetzel G, Jardine AG, Locatelli F, Maes BD, Mercer A, Ortiz F, Praga M, Sørensen SS, Tesar V, Del Vecchio L; NEFIGAN Trial Investigators: Targeted-release budesonide versus placebo in patients with IgA nephropathy (NEFIGAN): a double-blind, randomised, placebocontrolled phase $2 \mathrm{~b}$ trial. Lancet 2017;389: 2117-2127.

32 Lv J, Shi S, Xu D, Zhang H, Troyanov S, Cattran DC, Wang H: Evaluation of the Oxford Classification of IgA nephropathy: a systematic review and meta-analysis. Am J Kidney Dis 2013;62:891-899.

33 Sarcina C, Tinelli C, Ferrario F, Pani A, De Silvestri A, Scaini P, Del Vecchio L, Alberghini E, Buzzi L, Baragetti I, Pozzi C: Changes in proteinuria and side effects of corticosteroids alone or in combination with azathioprine at different stages of IgA nephropathy. Clin J Am Soc Nephrol 2016;11:973-981. 